\title{
Bir Olasılıktan Ötekine Köprü
}

Doç. Dr. Adil Korkmaz ${ }^{1 *}$

Geliş tarihi: 01.07.2019

Kabul tarihi: 03.09.2019

\section{Attf bilgisi: \\ IBAD Sosyal Bilimler Dergisi \\ Sayı: Özel Sayı Sayfa:143-151}

Yıl: 2019

This article was checked by $i$ Thenticate. Similarity Index 1\%

1 Akdeniz Üniversitesi İktisadi ve İdari Bilimler Fakültesi Ekonometri Bölümü, Türkiye, adilkorkmaz@akdeniz.edu.tr. ORCID 0000-0002-2432-518X

* Sorumlu yazar

\section{öz}

$\mathrm{Bu}$ çalışmada öznel ve nesnel olasılıklar arasındaki işbirliği koşulları incelenmektedir. Burada işbirliği sözcüğü ile anlatılmak istenen, olasılıklardan biri belli iken öbürünü de belli etmektir. Olasılık kuramının ilk zamanlarında böyle bir sorun yoktur; çünkü o zamanlarda tek olasılık vardır, o aynı anda hem öznel hem de nesnel olasılıktır, büyük sayılar yasası onlardan birinin öbürüne eşit olmasını garanti etmektedir, bu da demektir ki olasıllklardan biri belli iken öbürü de bellidir. O günlerdeki işbirliğine mutlak işbirliği denebilir. Bugün yalnızca koşullu işbirliği kabul edilebilir niteliktedir. Bu çalışma söz konusu koşullu işbirliğini incelemeyi amaçlamaktadır.

Anahtar Kelimeler: Olasılık, Öznel Olasılık, Nesnel Olasılık, İşbirliği. 


\title{
Bridge from One Probability to Another
}

\author{
Assoc. Prof. Dr. Adil Korkmaz ${ }^{1^{*}}$
}

First received: 01.07.2019

Accepted: 03.09.2019

\section{Citation:}

IBAD Journal of Social Sciences

Issue: Special Issue Pages:143-151

Year: 2019

This article was checked by iThenticate.

\section{ABSTRACT}

This study examines the conditions of cooperation between subjective and objective possibilities. Here, the intended goal to express the word of collaboration is to make one probability known when the other is known. There was no such problem in the early days of probability theory; because there is only one possibility at that time, it is both subjective and objective at the same time, the law of large numbers guarantees that one of them is equal to the other, which means that while one of the probabilities is certain, the other is obvious too. Cooperation in those days can be called absolute cooperation. Today, only conditional cooperation is acceptable. This study aims to examine this conditional cooperation.

Keywords: Probability, Subjective Probability, Objective Probability, Cooperation.

${ }^{1}$ Akdeniz University, Turkey, adilkorkmaz@akdeniz.edu.tr ORCID 0000-0002-2432-518X.

* Corresponding Author 


\section{GíRIŞ}

\section{SITKI BEY:}

İslam Bey, bu gece bir yere gidecek. Beraber gidebilir misin? Fakat yüzde doksan dokuz kurşuna dizilmek var. ABDULLAH ÇAVUS:

Kurşuna dizilirsem kıyamet mi kopar.

(Namık Kemal, Vatan yahut Silistre).

Öznel ve nesnel olmak üzere iki olasılık vardır. Bu olasılıklar şu ya da bu bakımından birbirlerine ne ölçüde çok benzerlerse benzesinler anlamca bambaşkadırlar. Bunu görebilmek için Namık Kemal'in Vatan yahut Silistre adlı yapıtından alıntılanan yukarıdaki tümceleri incelemek bile yeterlidir. Söz konusu tümcelerde geçen 0.99 (yüzde doksan dokuz) sayısı iki farklı biçimde anlamlandırılabilir: Birincisi, Sıtkı Beyin ya da Abdullah Çavuşun kurşuna dizilmelerindeki kolaylık düzeyi; ikincisi ise aynı kişilerin kurşuna dizileceklerine duyulan inancın yüksekliğidir. Birinci anlamlandırma nesnel olasılığı, ikinci anlamlandırma da öznel olasılığı yansıtır. Yukarıdaki örnekte de görüleceği üzere nesnel olasılık "olmaktaki kolaylık" biçiminde tanımlanır ise de "uzun dönemdeki göreceli sıklık" ile nicelleştirilir. Öznel olasılık da da farklı yöntemlerle nicelleştirilebilir. Kimi yazarlar bir yönüyle öznel, bir başka yönüyle de nesnel gerçekliğe bakma özelliğinden ötürü olasıllı̆ı Roma tanrısı Janus'a benzetirler; çünkü Roma tanrısı Janus da bir yüzüyle geçmişe, öbür yüzüyle geleceğe bakmaktadır. Ian Hacking anılan benzerliği anlatabilmek için 1975 yllında yayınlanan "Olasıllı̆ın Doğuşu (The Emergency of Probability)" adlı yapıtında Janus yüzlü olasılık (Janus faced probability)" tamlamasını kullanır (Hacking, 1991, s. 12). Bu tamlamayı daha önce kullanan Cooper (1965) gibi başka yazarlar da vardır; ancak Daston (1994) ve Gillies (2000, s. 18) de içinde olmak üzere pek çok yazar söz konusu tamlamayı kullandıklarında Cooper'e değil, Hacking'e gönderme yapmaktadırlar. Bundan da anlaşılmaktadır ki, Ian Hacking, Janus yüzlü olasılık tamlamasının yaratıcısı olan değil ise de tutulurluğunu yükselten kişidir.

\section{1. İKI OLASILIK ARASINDA İşBİRLİĞí}

1945 y1lı ile başlayan dönemde Viyana Çevresinin yıldızı Rudolf Carnap yukarıda dile getirilen iki olasılığın her ikisini de bilim açısından yararlı ve gerekli diye nitelendirir (Carnap, 1945a; 1945b). Bu da onu geçmişteki matematikçilerden ve filozoflardan farklı bir konuma oturtur. Çünkü bu düşüncesinin bir sonucu olarak o artık iki olasılık arasında bir çatışma değil, işbirliği arama yolunu seçer. İki olasılık arasında işbirliği yapmak demek olasılıklardan biri belli iken ötekini de belli etmek demektir. Bunun da iki biçimi olabilir: Bir, öznel olasılık belli iken nesnel olasılığı belli etmek; iki, nesnel olasılık belli iken öznel olasılığı belli etmek. Bu iki durumun gerçekleştirilebilmesi için her iki olasılığın da var olması gerekir. Kimi durumlarda öznel olasılık vardır ancak nesnel olasılık yoktur. Olan bir nicelik ile olmayan bir nicelik elbette eşleştirilemez. Bu durum şöyle örneklendirilebilir: Bir kişi "Evren genişlediğine göre çok büyük bir olasılıkla başlangıçta big bang (büyük patlama) vardır." gibi bir tümce söylemiş olsun. Bu tümcedeki geçen "çok büyük bir olasılıkla" anlatımındaki olasılık sözcüğü öznel olasılığı yansıtır ve o da $\mathrm{e}=$ "Evren genişliyor." gibi bir kanıt karşısında $\mathrm{h}=$ "Başlangıçta big bang vardır." gibi bir ilerisürüme ne ölçüde yüksek düzeyde inanıldığını gösterir. Burada konu açısından önemli olan, ne ölçüde büyük olduğu belirtilmemekle birlikte çok büyük diye nitelendirilebilen bir öznel olasıllğın varlığıdır. Oysa evrenin big bang ile başlayıp başlamamasıyla ilgili nesnel olasılık yoktur. Dolayısıyla iki olasılık arasında eşleştirme de söz konusu değildir.

Olasılıkların eşleştirilemeyecekleri durumlardan biri de onların birbirlerine eşit olmadıkları durumlardır. Şu örnek bu durumu anlatmak için uygundur. Bir torbada siyah ya da beyaz olduğu bilinen ancak hangi renk olduğu bilinmeyen bir kurdele olsun. "Bu torbadan beyaz kurdele çekme olasıllı̆ı kaçtır?" sorusuna verilecek iki yanıt vardır. Öznel olasılığı yansıtan 0.5 ve nesnel olasılığı yansıtan 0 ya da 1 . Birinci yanıt öznel olasılı̆̆ yansıtır; çünkü kurdelenin ne renk olduğu bilinmediğinden "Çekilecek kurdele beyazdır." ve "Çekilecek kurdele siyahtır." ilerisürümleri eşit ölçüde inanılabilir niteliktedirler ve dolayısıyla da kayıtsızlık ilkesi uyarınca onlara 0.5 olasılıklarını atamak gerekir. 0 ' dır ya da 1 'dir yanıtı ise sıklıkçı bir özellik sergileyen nesnel olasılığı yansıtır. Torbadaki kurdele beyaz ise beyaz kurdele çekme sıklığı 1 , tersi durumda ise 0 olur. Bu örnekte öznel olasıllk 0.5 olarak belirlenebilirken nesnel olasilık 0 ya da 1 
olarak iki seçenek biçiminde belirlenebilmektedir ve bunları birbirlerine eşleştirmek farklı sayıları eşitlemek gibi bir kabul edilemez işlem olmaktadır.

Öyleyse iki olasılık arasında bir eşleştirme yapabilmek için ilk olarak gerekli iki koşul ileri sürülebilir: Bir, olasılıkların ikisi de var olmalıdır; iki, onların birbirlerinden farklı oldukları konusunda bir bilgi olmamalıdır. Bu koşullar sağlanmışken olasılıklardan biri belli iken öbürünün belli edilip edilemeyeceği sorusu yöneltilebilir.

\section{2. ÖZNEL OLASILIK BELLIYYKEN NESNEL OLASILIĞI BELLİ ETMEK}

Olasılık kuramının doğuş döneminde a priori (önsel, gözlemden önce) olarak elde edilen öznel olasılık ve $a$ posteriori (sonsal, gözlemden sonra) olarak elde edilen nesnel olasılık büyük sayılar yasası gereğince eşit değerde olmaktadırlar. O nedenle söz konusu dönemde anılan olasılıklardan biri belli iken öteki de belli olmaktadır. Bu da demektir ki olasılık kuramının doğuş döneminde olasılıklardan biri belli ilen ötekini de belli etmek gibi bir sorun yoktur. Anılan dönemde a priori olasılığ 1 belirlemek için eşolabilirlik ilkesi (the principle of equipossibility) kullanılır. Bu ilkeye göre bir denemedeki sonuçlar eşolabilir niteliktedirler. Eş-olabilirlik eşit ölçüde kolay gerçekleşebilirlik demektir. Burada şu soruyu yöneltmek gerekir: Bir denemedeki sonuçların gerçekleşme kolaylıklarının eşit olması ne demektir? Gerçekleşme kolaylığı insana özgü bir kavramdır. Evrene değil... Örnek olarak insan açısından bir okka (1283 gram) odunu kaldırmak kolay, yüz okka odunu kaldırmak zordur. Oysa evren açısından kolay ya da zor yoktur. Olaylar koşullar tamamsa gerçekleşirler, tamam değil ise gerçekleşmezler. Koşullar tamam ise dağlar yerinden oynar, tamam değilse bir yaprak bile dalından kopmaz. Gerçekleşen olayların daha kolay ya da daha zor gerçekleştiklerini söyleyebilmek için evreni kişileştirmek gerekir. Kişileştirme anlatılmaz olanı anlatabilmek için yararlanılan yazınsal bir sanattır. Bu sanattan yararlanmak eşolabilirlik kavramındaki bulanıklı̆g 1 azaltsa bile büsbütün yok edemez. Pierre-Simon Marquis de Laplace eşit ölçüde karar verilemezlik gibi öznel bir kavramı eş-olabilirlik gibi nesnel bir kavrama duruluk özelliğini kazandırabilmek için dile getirir; ancak bu yolla sağlanan başarının sınırlı olduğunu belirtmek gerekir. Çünkü öyle durumlar vardır ki onlarda eşit ölçüde karar verilemezlik ile eş-olabilirlik örtüşmez. Yönelimli para örneği bunlardan yalnızca biridir. Yazıya ya da turaya yönelimli olduğu bilinen ancak bunlardan hangisine yönelimli olduğu bilinmeyen bir madensel para havaya atıldığında bu paranın ne geleceği konusunda bir karar verilemezlik söz konusu olur. Kayıtsızlık ilkesi uyarınca "Yazı gelecek." ilerisürümüne ne ölçüde inanılabilirse "Tura gelecek." ilerisürümüne de o ölçüde inanılabilir. Bu da demektir ki "Yazı gelecek." ilerisürümüne 0.5 olasılığı iliştirilir; bu olasılık elbette "Madensel para yazıya da turaya da yönelimli olabilir." gibi bir kanıta dayalı olduğu için öznel olasılığın mantıksal türüne girer. Yukarıdaki örnekte mantıksal olasılık 0.5 olmakla birlikte nesnel olasılık (yazı gelmenin uzun dönemdeki göreceli sıklığı) öyle değildir. Bunun nedeni madensel paranın yönelimlilik özelliğidir. $\mathrm{Bu}$ özellik madensel paranın yazı ile tura yüzlerinin eşolabilirlik ilkesine aykırı olmaları demektir. Böyle bir durumda yazı gelmesine ilişkin nesnel olasılığın 0 ile 1 aralığındaki her sayıya eşit olabileceği ancak 0.5 sayısına asla ve asla eşit olamayacağı söylenebilir. Bu örnek de gösterir ki eşit ölçüde karar verilemezlik ve eşolabilirlik ilkelerinin örtüşmedikleri durumlarda mantıksal nitelikteki öznel olasılık belliyken nesnel olasılığ belli etmeye çabalamak tehlikelerle dolu bir yola girmekten başka bir anlama gelmez. Bu konuda başka örnekler de sergilenebilir. Eşit ölçüde karar verilemezlik ilkesi birden çok $a$ priori olasılık üretilebilir ancak eşolabilirlik ilkesi yalnızca birtek a posteriori olasılık üretir. Bu da öznel olasılığın çok, nesnel olasılığın tek olması anlamına gelir ki böyle bir durumda iki olasılık arasında işbirliği yapmak tehlikelerle dolu bir yola girmekten başka bir anlama gelmez. Bertrand tutmazlıkları (paradox) bu konudaki en ünlü kanttlardan biri olarak değerlendirilebilir (Gnedenko, 1978, s. 34-36). Bu tutmazlıklarda bir çember içine çizilen en büyük eşkenar üçgenin kenar uzunluğu ile o çemberi kesen bir kirişin uzunluğu karşılaştırılır. Bu karşılaştırmada kiriş uzunluğunun kenar uzunluğundan daha büyük olma olasılığ 1 araştırılır ve üç farklı olasılık sayısı elde edilir. Bunlara mantıksal olasılıklar olarak bakılabilir; çünkü farklı kanıtlar altında farklı mantıksal olasılıklar doğar. Bunlardan birine nesnel olasılık olarak da bakılabilir ancak bunların hepsine birden nesnel olasılık olarak bakılamaz. Çünkü uzun dönemdeki göreceli siklık olarak nesnel olasılık tektir. Bertrand tutmazlıklarının matematiksel yordamı zor görünebilir ancak öğrencilere yöneltilen şu sorunun matematiksel yordamı kolaydır: İki çocuklu bir aile üyesi olan prensin kardeşinin bir prenses olma olasılığı kaçtır? Öğrenciler bu soruyu iki farklı biçimde çözebilmektedirler: Birinci çözüm şöyle olmaktadır: Prensin bir kardeşi olduğuna göre bu kardeş ya prenstir ya da prensestir. Bütün durumların sayısı 2'dir. Prenses 1 durumda olduğuna göre 
uygun durum sayısı 1'dir. O nedenle prensin kardeşinin prenses olma olasıllı̆g 1/2'dir. İkinci çözüm de şöyledir: Prens iki çocuklu bir aile üyesi olduğuna göre böyle bir ailenin çocukları şöyle listelenebilir: Prenses Prenses, Prenses Prens, Prens Prenses, Prens Prens. Bu dört durumdan Prenses Prenses seçeneğini elemek gerekir; çünkü Prenses Prenses seçeneği bir prens çıkarmış aile için söz konusu değildir. Geriye kalan bütün durumların sayısı 3'tür. Bunlar içinde yalnızca iki durumda prenses olduğundan uygun durum sayısı 2'dir. $O$ zaman prensin kardeşinin prenses olma olasillğ 1 2/3 olur. Öğrenciler her iki olasılık değerini de eşit ölçüde karar verilemezlik ilkesini kanıt olarak kullanıp a priori olarak belirleyebilmektedirler. O nedenle söz konusu olasılıklar mantıksal olasılıklardır. Bunların başka başka değerlere sahip olmalarının nedeni dayandıkları kanıtların farklılıklarıdır. İlk çözümü geliştiren öğrencilerin dayandıkları kanıt şudur: Prensin kardeşinin prens ya da prenses olması eşit ölçüde karar verilemez durumlardır. Öbür çözümü geliştiren öğrencilerin dayandıkları kanıt ise şudur: Ailenin iki çocuğunun listelenmiş kümesindeki öğeler eşit ölçüde karar verilemez durumlardır.

Öznel olasılık -burada onun mantıksal türü- kullanılacak ise o zaman nesnel olas1lık 1/2 olarak mı, yoksa $2 / 3$ olarak mı belli edilecektir. Öğretmenleri öğrencilerine birinci çözümün yanlış, ikinci çözümün doğru olduklarını söyleyeceklerdir. Bunu söylerken düşündükleri olasılık doğallıkla nesnel olasılıktır. Birinci çözümü geliştiren öğrencilerin hata içine düştükleri kabul edilecek olursa o zaman bu tür hatalara ünlü matematikçilerin de düştükleri göz önünde tutularak bir avuntu elde edilebilir. Avuntu elde edilecek matematikçilerden biri de Jean le Rond d'Alembert'tir. O, şu soruyu çözerken yukarıda dile getirilene benzeyen bir hata içine düşer (Gorroochurn, 2011): İki hilesiz madensel para havaya atılıyor. En az birinin yazı gelmesi olasılığı nedir? Jean le Rond d'Alembert bu soruyu yanıtlarken eşit ölçüde karar verilemez olan sonuçlar kümesini:

$\{\mathrm{YY}, \mathrm{YT}, \mathrm{TY}, \mathrm{TT}\}$

biçiminde değil de:

\section{$\{\mathrm{YY}, \mathrm{YT}, \mathrm{TT}\}$}

biçiminde gösterir. Burada Y harfi Yazı, T harfi de Tura kısaltması olarak kullanılmaktadır. Jean le Rond d'Alembert TY'yi YT'den farklı olarak değerlendirmediği için sonuçlar kümesini 4 değil de 3 öğeli olarak tasarlar. Bunun sonucu olarak da havaya atılan iki madensel paradan en az birinin yazı gelmesi olasılığını 2/3 olarak bulur. Eşit ölçüde karar verilemez sonuçlar kümesi bugün kabul edildiği gibi:

$\{$ YY, YT, TY, TT $\}$

biçiminde gösterilirse o zaman havaya atılan iki madensel paradan en az birinin yazı gelmesi olasıllğ $3 / 4$ olarak hesaplanır. Gerek 2/3, gerekse 3/4 sayıları farklı kanıtlara göre bulunmuş farklı mantıksal olasılıklar olarak değerlendirilebilir. Acaba nesnel olasılık bunlardan birine eşit midir? Eşit ise hangisine? Bugün bu sorular kolayca yanıtlanabilir: Nesnel olasıllk 3/4 sayısına eşittir ve bu da Jean le Rond d'Alembert'in çözümünden farklı olan bir ölçüdür. Karl Pearson "İstatistik Tarihi (History of Statistics)" adlı yapıtında Jean le Rond d'Alembert'in olasılık konusuna ne katkısı olduğunu sorar ve onun yukarıdaki çözümünü göz önünde bulundurarak bu sorusuna "Kesinlikle hiç! (Absolutely nothing!)" yanitını verir (Gorroochurn, 2011). Karl Pearson'un bu yanıtında mantıksal olasılık konusundaki olumsuz tutumunun bir rolü olmalıdır. Burada konu açısından önemli olan şudur: Farklı kanıtlara göre birden çok mantıksal olasılık ölçüsü elde edilebilirken nesnel olasılık ancak ve ancak tek bir ölçü olarak elde edilebilir. $\mathrm{O}$ da uzun dönemdeki göreceli sıklıktan başka bir nicelik değildir. Bu da demek olmaktadır ki mantıksal olasılık belli iken nesnel olasılığı belli etmeye çabalamak tehlikelerle dolu bir yaklaşım içinde olmaktır (Geleneksel olasılık tanımı için bkz. Miller-Miller, 2014, s. 21-60).

Benzer bir söz öznel olasıllı̆̆n ruhbilimsel türü için de söylenebilir. 20. yüzyılda Frank Plumpton Ramsey ile Bruno de Finetti'nin savundukları ruhbilimsel olasılığın ölçümünde yitirilecek değerin kazanılacak değere oranı kullanılır (Gillies, 2000, s. 50-87). Bu oran bahis oranıdır. Burada yitirilecek değer, bir ilerisürüme olasılık atayan oyuncunun masaya koyduğu değerdir. Kazanılacak değer ise masadaki toplam değerdir. Toplam değer oyuncunun ve karşı oyuncunun masaya koydukları değerler toplamıdır. Yitirilecek değerin kazanılacak değere oranı ruhbilimsel olasılıktır. Bu olasılık şöyle örneklendirilebilir: Bir ruhbilimci, bir kumarseverin "Yazı gelecek." ilerisürümüne ne ölçüde inandığını ölçmek için masaya 1 birim para koyar. Kumarsever de masaya 2 birim para koyar ise kumarsever 
açısından masaya koyduğu bu 2 birim para yitirilecek değerdir. Kumarsever "Yazı gelecek." ilerisürümü konusunda haklı çıkarsa masadaki toplam $1+2=3$ birim parayı kazanır. Dolayısıyla bu durumda ruhbilimsel olasılık 2/3 olur. Oysa havaya atılan hilesiz bir madensel paranın yazı gelme ile ilgili nesnel olasıllğı 1/2 olmaktadır. Görüldüğü gibi, bu örnekte ruhbilimsel olasılık nesnel olasılığa eşit değildir. Kumarsever, daha çok yitinçlerle karşılaşılan bir dizi yaşantıdan sonra 1 birim paraya karşılık 2 birim para koyarak oynayacağı bir kumardan kazançlarla kalkamayacağını görebilir ve bu nedenle böyle bir durum ile yüz yüze gelmemek için koyduğu parayı azaltıp 1 birim paraya dek düşürebilir. $\mathrm{Bu}$, artık "Yazı gelecek." ilerisürümüne eskisi ölçüsünde inanmadığının bir kanıtı olur; çünkü artık onun ruhbilimsel olasılığ 1 1/2 olmuş olur. Nesnel olasılık hâlâ 1/2'dir ve bu durumda görülür ki ruhbilimsel olasılık nesnel olasılığa eşittir. $\mathrm{Bu}$ örnek şunu kanıtlamaktadır ki öğrenme yoluyla değişebilen ruhbilimsel olasılık belli olduğunda hep sabit kalan nesnel olasılığı onun aracılığıyla belli etme yolu tehlikelerle dolu bir yoldur.

\section{NESNEL OLASILIK BELLIYKEN ÖZNEL OLASILIĞI BELLİ ETMEK}

Nesnel olasılık belli iken öznel olasılık da belli edilebilir. Nitekim öznel olasılı̆̆ı belirlemede kullanılan araçlar arasında nesnel olasılık başlarda gelir. $\mathrm{Bu}$, Gottfried Wilhelm Leibniz'in şu sözünü gerçekleştirmekten başka bir anlam taşımaz (Hacking, 1991, s. 128):

Quod facile est in re, id probabile est in mente (Bir olay evrende nice kolay olursa biz de onun gerçekleşeceğine onca çok inanırız.)

Gottfried Wilhelm Leibniz kısaca şunu söylemektedir: Nesnel olasıllk öznel olasıllğa eşittir. Bu söz olasılıklardan birini ötekine ayrılmaz bir biçimde olmak üzere kavuşturmayı amaçlayan bir anlatımdır. Burada koşula bağlı olmadığı için mutlak diye nitelendirilebilecek olan böyle bir eşleştirmenin (işbirliğinin) 20. yüzyıldaki ilk örneklerinden birini Carl Gustav Hempel vermiş olur. $\mathrm{O}$, geliştirdiği açıklama ve öngörme yordamlarının bir çeşidinde Gottfried Wilhelm Leibniz'in sözünü uygular:

a) Örnek Bir Öngörme Yordamı: Bay/Bayan X nasıl davranacak?

(i) Bir din üyesi olan bir kişi başka inanç topluluğu içinde yaşarken güvende olmayı büyük bir olasılıkla o inanç topluluğunun üyesiymiş gibi görünerek ikiyüzlü olmakta bulur.

(ii) Bay/Bayan X bir din üyesi olup başka bir inanç topluluğu içinde yaşayan bir kişidir.

(iii)

Bay/Bayan X büyük bir olasılıkla güvende olmayı o inanç topluluğunun bir üyesiymiş gibi görünerek ikiyüzlü olmakta bulacaktır.

Öngörme yordamı henüz olup bitmemiş olayların nasıl olup biteceklerine ilişkin tümceler yaratabilme etkinliğidir. $\mathrm{Bu}$, tümdengelimsel-yasaya dayalı (Deductive-Nomological "kısaca D-N") öngörme yordamı için geçerli olduğu gibi tümevarımsal-olasılığa dayalı (Inductive-Statistical "kısaca I-S") öngörme yordamı için de geçerlidir. Yukarıdaki örnek ikinci çeşit öngörme yordamıdır. Bu yordamda bir olasılıksal yasayı dile getiren ilk tümcedeki \%90 sayısı uzun dönemdeki göreceli sıklık ile ölçülen nesnel olasılıktır. Carl Gustav Hempel bunu eğilim (disposition) diye adlandırır ki o da Karl Raimund Popper'in yönelim (propensity) adlandırması ile benzerlik gösterir. Vargıdaki $\% 90$ sayısı ise günde dört paket sigara içen Bay/Bayan X'in kanser hastalığına yakalanacağına duyulan inanç yüksekliğini yansıttığından öznel olasılıktır. Yukarıdaki I-S öngörme yordamı şunu kanıtlamaktadır: Böyle bir bilimsel etkinliği gerçekleştirilebilmesi öznel olasılığın nesnel olasılık yardımıyla belirlenebilmesi ile olur. Benzer bir iş açıklama yordamı için de yapılabilir:

b) Örnek Bir Açıklama Yordamı: Bay/Bayan X neden intihar etti?

(i) Herhangi bir kişi sevdiğine kavuşma umudunu yitirir ise o kişi çok yüksek bir olasılıkla intihar eder.

(ii) Bay/Bayan X sevdiğine kavuşma umudunu yitiren bir kişidir.

Bay/Bayan X çok yüksek bir olasılıkla sevdiğine kavuşma umudunu yitiren bir kişi olduğu için intihar etti. 
Açıklama yordamı olmuş bitmiş bir olayın neden olup bitmiş olduğuna ilişkin tümceler yaratabilme etkinliğidir. Hempel (1965) bu etkinliğin de D-N ve I-S biçimlerini anlatır. Her iki biçim de en az bir yasa tümcesine ve gene en az bir başlangıç koşulu tümcesine dayalıdır. Yukarıdaki açıklama yordamı I-S açıklama yordamına ilişkin bir örnektir. Bu yordamda ilk tümce olasılıksal yasayı dile getiren bir tümcedir. Bu tümcedeki "çok yüksek bir olasılıkla anlatımı nesnel olasılığa ilișkin bir anlatım iken vargı tümcesindeki aynı anlatım öznel olasılığa ilişkin bir anlatımdır. Bu yordamda öznel olasılık daha önce belli edilmiş olan nesnel olasılık aracılığıyla belli edilmektedir.

Öznel olasılığın nesnel olasılık aracılı̆̆ıyla belli edilmesinde dayanak sınıf (reference class) sorunu vardır. Her dayanak sınıf için başka bir nesnel olasılık söz konusu olduğundan dayanak sınıfını hatalı olarak belirlemek demek nesnel olasılığı hatalı olarak belirlemek ve dolayısıyla da öznel olasılığ hatalı olarak belirlemek demektir. Öznel olasılığı nesnel olasılık aracılı̆̆ıyla belli etme sorununun çözümü dayanak sınıfı sorununun çözümüne bağlıdır. Bu durum şöyle bir soru yönelterek örneklendirilebilir: Kırkıncı yaşını tamamlamış olan Bay X'in kırk birinci yaşını tamamlayacağına ne ölçüde inanılabilir? Bu soru "Kırkıncı yaşını tamamlamış olan Bay X kırk birinci yaşını tamamlayacaktır." ilerisürümüne hangi öznel olasıllı̆ın atanacağını sorgulayan bir sorudur. Burada sorgulanan öznel olasılığı belli etmek için önce nesnel olasılığı belli etmek gerekir. Bunun için ise farklı dayanak sınıflarına göre farklı yollar izlenebilir. Bunlardan biri önce insanlar arasında kırkıncı yaşını tamamlayanları, sonra da bunlar arasında kırk birinci yaşını tamamlayanları saymak ve elde edilen sayılardan ikincisini birincisine oranlamaktır. Bay X hakkında hiçbir bilgi yoksa bu yol önerilebilecek bir yol olarak kendisini ortaya koyar. Ancak Bay X'in Japon olduğu bilgisi varsa yukarıdaki yol artık önerilemeyecek nitelikte olur; çünkü kırkıncı yaşını tamamlayanların kırk birini yaşını da tamamlayabilme olasılığı ülkeden ülkeye değişebilir. Bay X hakkında Japon olduğu bilgisi varsa dayanak sınıfını değiştirmek artık kaçınılmazdır. Dayanak sınıf şimdi insanlar sınıfı değil, Japonlar sınıfıdır. Bu dayanak sınıfına ilişkin nesnel olasılığı belli etmek için şimdi yapılacak iş yukarıdaki işlemleri bu dayanak sınıf için yinelemektir. Bay X hakkındaki her bilgi dayanak sınıfını değiştirebilir. Ancak değiştirmeyebilir de. Örnek olarak Bay X'in kel olduğu bilgisi varsa bu bilgi dayanak sınıfını değiştirmeyebilir. Bunun nedeni $\mathrm{A}=$ "kel olma" ile $\mathrm{B}=$ "kırkıncı yaşını tamamlamışken kırk birinci yaşını tamamlama" olayları arasında bir ilginin olmaması biçiminde betimlenebilir. $\mathrm{Bu}$ durum olasılık matematiğinde $\mathrm{P}(\mathrm{B} / \mathrm{A})=\mathrm{P}(\mathrm{B})$ diye dile getirilir. $\mathrm{A}, \mathrm{B}$ ile ilgili olasıllı̆ ne artıran ne de eksilten bir olaydır. Bu özellikteki olaylar konusundaki bilgiler nesnel olasıllk yardımıyla öznel olasılığı belirlemede engel oluşturmayan bilgilerdir ve olasılık eşleştirmesi bakımından kabul edilebilir bilgiler diye nitelendirilir (Lewis, 1980; Strevens, 1995). Olasıllı̆ı artıran ya da eksilten olaylara ilişkin bilgiler olasılık eşleştirmesi bakımından kabul edilemez bilgiler diye nitelendirilir. Böyle bilgiler arasında kristal küre (crystal ball) bilgileri başlarda gelir. Masallardaki kristal küreler hangi olayın gerçekleştiğini ya da gerçekleşeceğini gösteren cisimlerdir. Cadılar kristal kürelerine bakarlar ve hangi olayın gerçekleştiğini ya da gerçekleşeceğini görüp söylerler. Bilimdeki kristal küreler hangi olayın gerçekleştiğini ya da gerçekleşeceğini gösteren tümceler topluluğudur. Bu tümcelerin bir bölümü doğa yasalarını, öbür bölümü de doğaya ilişkin başlangıç koşullarını dile getirirler. Böyle tümceler topluluğuna sahip olan bir kişi hangi olayın gerçekleştiğini ya da gerçekleşeceğini bilebileceğinden onun açısından öznel olasılık ya 0 ya da 1 olur. Asla aradaki değerler olmaz. Romatizma ağrıları yağmurun yağacağını kesin olarak gösteren bir kristal küre olarak değerlendirilirse o zaman televizyonda hava durumu raporunu dinleyen romatizmalı bir kişi "Bugün yağmur yağma olasılığı 1/2'dir." haberini dinledikten sonra öznel olasılığını 0.5 olarak belirlemez, romatizma ağrları varsa 1 , yoksa 0 olarak belirler. Romatizmalı olmayan bir kişi ise kristal küreden yoksun bir insan olarak öznel olasıllı̆ını hava durumu raporuna göre 0.5 biçiminde belirleyebilir. Burada kristal küre olarak işlev gören tümce "Yağmurdan önce havada gerçekleşen fiziksel ve kimyasal değişimler romatizma ağrılarını depreştirir." gibi bir doğa yasası (law of nature) ya da doğa yasası benzeri (lawlike) niteliğindeki bir sözdür. Herakleitos'un bu ve bunun gibi sözleri logos sözcüğü altında topladığı bilinmektedir (Herakleitos, 2005, s. 29). Genel olarak doğa yasaları birer kristal küre parçası olarak işlev görebilirler. Herhangi bir doğa yasasının kristal küre parçası olma işlevini nasıl gerçekleştireceği konusu şöyle örneklendirilebilir: Doğa yasası e="Isıtılan bir tel uzar." ve bir ilerisürüm h="Şimdi şurada isıtılan tel uzayacak." olduğuna göre $\mathrm{p}(\mathrm{h} / \mathrm{e})=1$ eşitliğinin yazılabilmesi doğa yasasının ilerisürüm konusunda bir kristal küre parçası olarak rol oynadığını gösterir. Pierre-Simon Marquis de Laplace'ın Demon'u en büyük kristal küreye sahip bir varlık olarak nitelendirilebilir; çünkü o bütün doğa yasalarını ve başlangıç koşullarını bilen bir varlık 
olarak kurgulanmaktadır. Bu olağanüstü varlığın penceresinden bakıldığında geçmiş gibi gelecek de besbellidir ve 0 ile 1 dışında olasılıklar yoktur (Hacking, 1991, s. 132).

Yukarıdaki örnekler öznel olasılığın nesnel olasılık aracılığıyla belirlenmesinin koşullara bağlı olduğunu göstermektedir. Bu koşulların neler olduğunu araştıran çalışmaların David Lewis (1980) ile birlikte ivmelendiği bilinmektedir. Onun çalışmaları başkalarınca da sürdürülür (Thau, 1994; Strevens, 1995; Strevens, 1999; Arntzenius vd., 2003). Anılan çalışmalarda öznel olasılık, 1654-1837 dönemindekinden farklı olarak bir koşula bağlı olarak nesnel olasılığı belirlemede kullanılır. Eşleştirme koşulu kabul edilemez bilginin yokluğudur.

\section{SONUÇ}

Nesnel olasılık belli iken öznel olasılı̆̆ı, öznel olasılık belli iken nesnel olasılı̆̆ı belli etmek olasılıklar arasında işbirliği olarak nitelendirilebilir. Her iki yaklaşımda da tehlikeler olduğunu gözden rak tutmamak gerekir. Nesnel olasılık belli iken öznel olasılığı belli etmede tehlike kaynağı kabul edilemez bilgidir. Kabul edilemez bilgi nesnel olasılık belli iken öznel olasılığı belli etmeyi gereksizleștirir. Çünkü öznel olasılığı belli etmek için nesnel olasılıktan daha çekici bir yol vardır, o da kabul edilemez bilgiden yararlanma yoludur. Olasılık eşleştirmesi bakımından kabul edilemez bilgiler arasında kristal küre bilgisi başlarda gelir. Böyle bir bilgiye sahip olma durumunda öznel olasıllğı yetkinlikle belirlemek varken onu nesnel olasılık aracılığıyla belirlemek önerilecek bir yol olarak görünmez. O nedenle öznel olasılığı belli etmede nesnel olasılıktan yararlanma yolu, ancak ve ancak kabul edilemez bilginin sağladığı daha çekici yollar yokken önerilebilir. Böyle bir yolu izlemek de bilimin temel nitelikteki açılama ve öngörme işlevlerini yerine getirmede eşsiz benzersiz yararlar sağlamaktadır. Son olarak bir başka tehlikeyi söz konusu etmek olanaklıdır. Bu tehlike öznel olasılık belli iken nesnel olasılığı belli etmededir. İki tehlikeye dikkat çekilebilir. Birincisi öznel olasılıkların çokluğuna karşılık nesnel olasılığın tekliğidir; ikincisi ise öznel olasılığın kanıta ya da kişiye göre değişirken nesnel olasılığın dayanak sınıfına göre değişmez kalmayı sürdürmesidir. Bu tür tehlikeler göz önünde bulundurulursa öznel olasılığı bilmenin nesnel olasılığı bilmeye sınırlı ölçüde yararlar sağladığı anlaşılabilir.

\section{KAYNAKÇA}

Arntzenius, F ve Hall, N. (2003). On what we know about chance. British Journal of Philosophical Science, 54(2), 171-179.

Carnap, R. (1945a). The two concepts of probability. Philosophy and Phenomenological Research, 5(4), 513-532.

Carnap, R. (1945b). On inductive logic. Philosophy of Science, 12(2), 72-97.

Cooper, Neil (1965). The concept of probability. The British Journal for the Philosophy of Science, 16(63), 226-238.

Daston, L. (1994). How probabilities came to be objective and subjective. Historia Mathematica, 21, 330-344.

Gillies, D. (2000). Philosophical theories of probability. Routledge: London and New York.

Gnedenko, B. V. (1978). The theory of probability (Translated from George Yankovsky). Moscow: Mir Publishers.

Gorroochurn, P. (2011). Errors of probability in historical context. The American Statistician, 65(4), 246254.

Hacking, I. (1991). The emergence of probability. Cambridge:Cambridge University Press.

Hempel, C. G. (1965). Aspects of scientific explanation and other essays in the philosophy of science. Toronto: Collier-Macmillan.

Herakleitos (2005). Fragmanlar (çev. Cengiz Çakmak). İstanbul: Kabalcı Yayınevi. 
Lewis, D. (1980). A subjectivist's guide to objective chance (Studies in Inductive Logic and Probability II içinde (Editor R. C. Jeffrey), Berkeley: University of California Press, 263-293.

Miller, I ve Miller, M. (2014). John E. Freund's mathematical statistics with applications. Edinburgh: Pearson Education Limited.

Mittelstaedt, P. ve Weingartner, P. A. (2005). Laws of nature. Berlin: Springer-Verlag.

Namık Kemal (2004). Vatan yahut Silistre \& zavallı çocuk (haz. Cengiz Yurt). Klas Yayınları: İstanbul.

Strevens, M. (1995). A closer look at the new principle. The British Journal for the Philosophy of Science, 46, 545-561.

Strevens, M. (1999). Objective probability as a guide to the world. Philosophical Studies, 95, 243-275.

Thau, M. (1994). Undermining and admissibility. Mind, 103, 491-505. 